\title{
A CASE OF GYRATE ATROPHY OF THE CHOROID \& RETINA
}

\author{
G. Satyavathi' ${ }^{1}$, Y. Srinivas ${ }^{2}$, Malleswari ${ }^{3}$
}

\section{HOW TO CITE THIS ARTICLE:}

G. Satyavathi, Y. Srinivas, Malleswari. "A Case of Gyrate Atrophy of the Choroid \& Retina". Journal of Evolution of Medical and Dental Sciences 2015; Vol. 4, Issue 06, January 19; Page: 1059-1062,

DOI: $10.14260 /$ jemds/2015/148

ABSTRACT: Gyrate atrophy of the choroid and retina is a rare chorioretinal degeneration inherited by on autosonal recessive mode of transmission. It is caused by mutation in gene for ornithine aminotransferase (OAT), located on chromosome 10. It is characterised by high myopia with astigmatism, night blindness during $2^{\text {nd }}$ and $3^{\text {rd }}$ decade with a slowly progressive posterior sub capsular cataract. Once diagnosed paediatrician/physician and Ophthalmologist should be aware of the follow up. No single therapy has been shown to halt the progression of the disease.

KEYWORDS: Gyrate Atrophy, High myopia, Night blindness, Ornithine Aminotransferase, Posterior sub capsular cataract.

INTRODUCTION: Gyrate atrophy (GA) is a rare, progressive metabolic choroidal and retinal degeneration inherited in AR inheritance pattern. It is due to deficiency of the pyridoxal phosphatedependent mitochondrial matrix enzyme ornithine aminotransferase (OAT) which results in hyperornithinaemia to levels 10-15fold above normal. In Finland gyrate atrophy occurs in about one in 50,000 individuals. However, the incidence of gyrate atrophy is less than one in 1,000,000 in rest of the world. In India, only two cases have been reported with confirmed biochemical assay. It is characterized by high myopia with astigmatism, night blindness during 2-3rd decade which is slowly progressive, early posterior sub capsular cataract.

The typical fundus shows sharply demarcated scalloped areas of atrophy of RPE \& choriocapillaries in mid periphery \& peripheral areas in a garland shaped fashion progressing to centrally as well as periphery. Visual field defects correspond to atrophic areas which finally coalesce to form ring scotoma. Other systemic abnormalities in GA are borderline low intellectual activity, mild proximal muscle weakness, peculiar, sparse scalp hair with areas of alopecia, and bizarre elongated segmented mitochondria in liver biopsies.

CASE HISTORY: A 22 yrs old male patient born out of consaguinous marriage presents with diminished vision since 15yrs. H/O night blindness for the past 2-3yrs.his visual acuity diminishing more for past 2 months. No h/o similar complaints in their family.

OCULAR EXAMINATION: VA- OU: CF 2mts with -6.50Dsph improving to 6/36, NV- N6.

SLIT LAMP EXAMINATION: OU- posterior subcapsular cataract present. Pupils are normal in size and sluggishly reacting to light. Rest of ant. Segment is normal. 


\section{CASE REPORT}

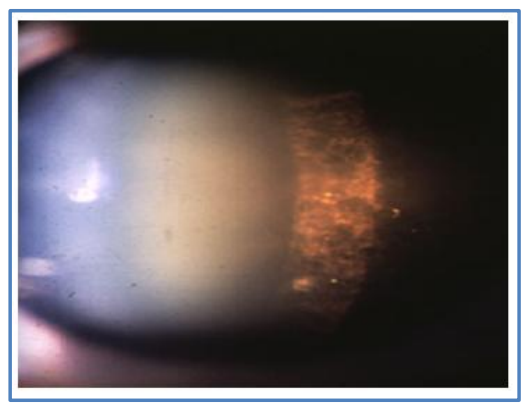

APPLANATION TONOMETRY: OD-16mmHg OS-18mmhg.

GONIOSCOPY: OU-open angles \& no abnormalities detected.

I/O EXAMINATION OF FUNDUS: OD - geographic atrophic patches of RPE and choriocapillaries with clearly demarcated scalloped borders in garland fashion in mid periphery, periphery \& some part of posterior pole. There is coarse pigmentation \& depigmentation of RPE with prominent large sclerotic choroidal vesseles.

OS-extensive atrophy of RPE \& choroicapillary without clear demarcation. Also there are areas of coarse pigmentation \& large choroidal sclerotic vessels are present.

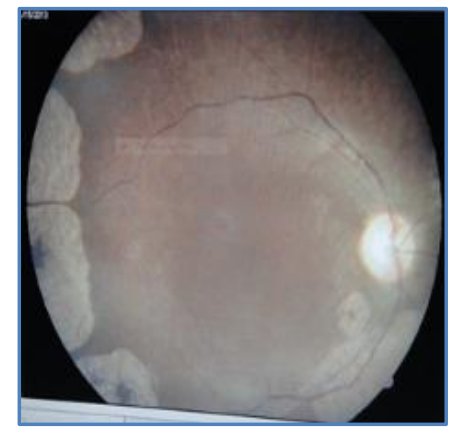

OD POSTERIOR POLE

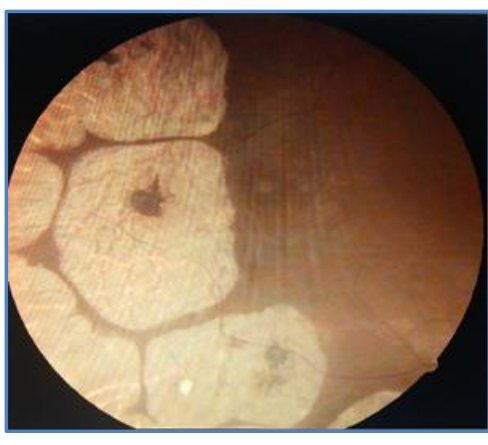

OD MID PERIPHERY

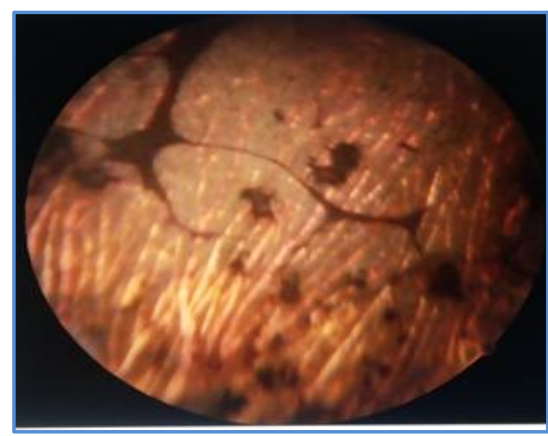

OD PERIPHERY

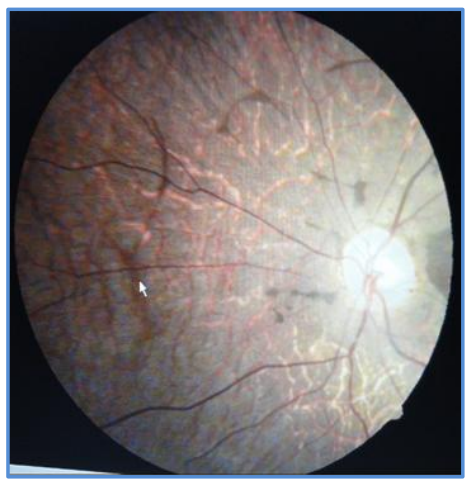

OS POSTERIOR AND MID PERIPHERY

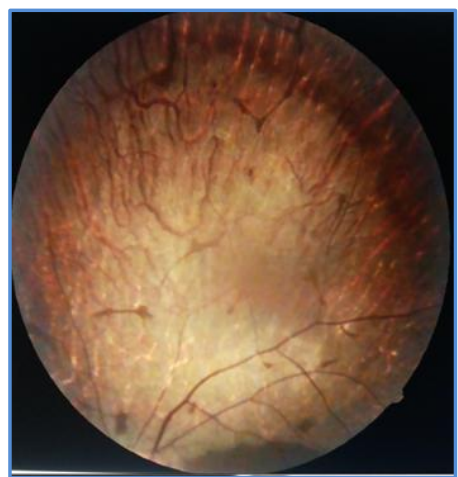

OS PERIPHERY 


\section{CASE REPORT}

SYSTEMIC EXAMINATION: normal.

EXAMINATION OF PARENTS \& SIBLING - no abnormality was detected.

IVESTIGATIONS: HVF- peripheral constriction of fields seen in OU, more in OS.

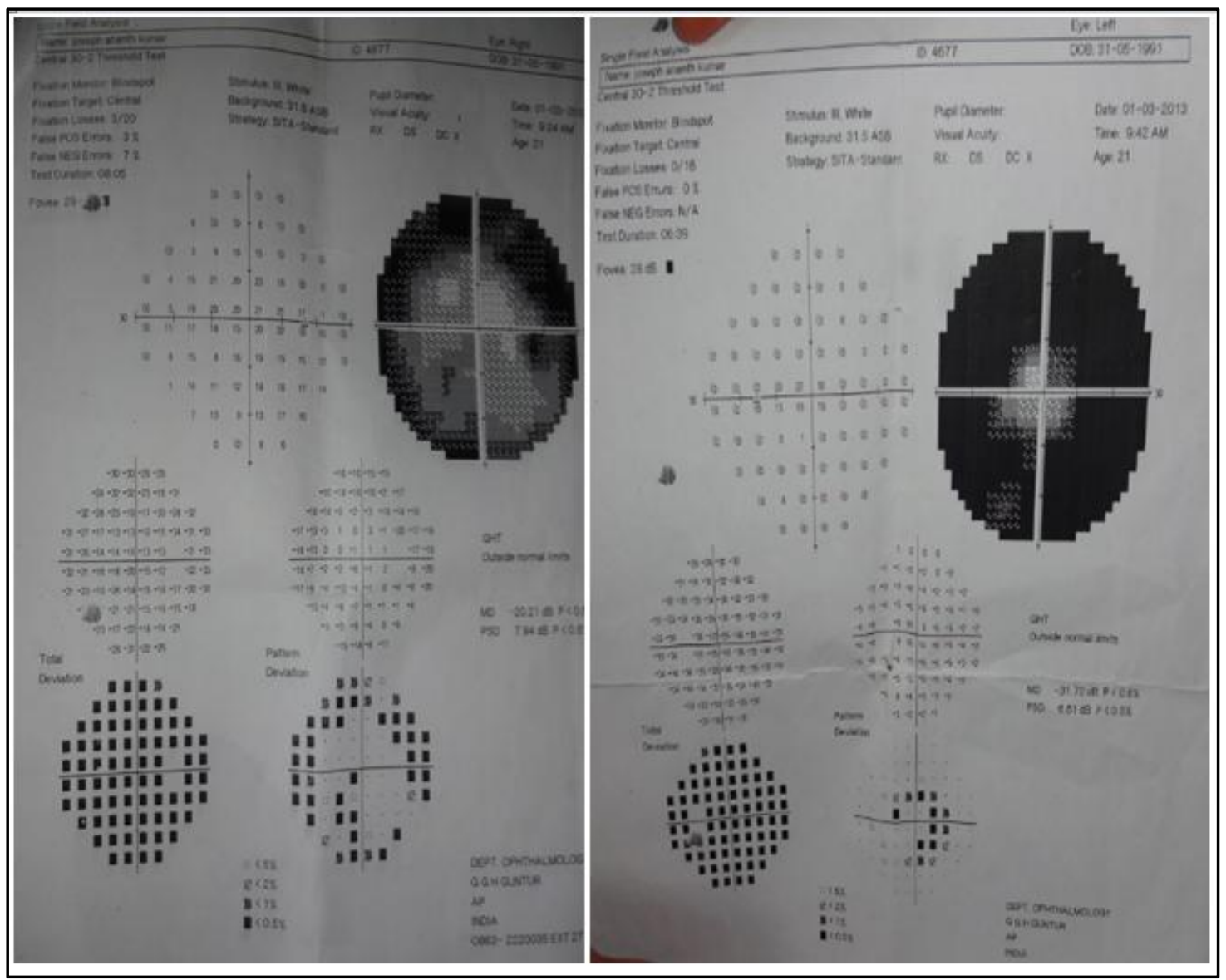

AMINOACID ANALYSIS FROM LALPATH LAB, MUMBAI: Elevated serum ornithine level 958micromoles/lt (Normal range 27-80micromoles/l).

2D ECHO: Normal.

ECG: Normal.

SERUM CREATININE: Normal.

DISCUSSION: This patient was presented at the age of 22yrs with defective vision BE on examination his VA-OU -CF-2mts with -6.50sph improving to 6/36 with posterior sub capsular cataract OU. On fundoscopy-revealed typical garland shaped arrangement of scalloped areas of chorio retinal atrophy mostly in mid periphery and also towards the equator \& posterior fundus. By this typical fundus picture we suspected diagnosis of gyrate atrophy and did various investigations. They revealed raised levels of serum ornithine \& constriction of peripheral fields which confirmed the diagnosis of gyrate 
atrophy. Pt was started immediately on low protein diet \& dietary supplementation of pyridoxine (B6) to slow progression \& advised regular follow up.

CONCLUSION: GA is one of the rare retinal degenerations once diagnosed both pediatricians and ophthalmologists should be aware of the importance of retinal examination, especially in high myopic children and the value of routine fundus examination in refractive patients. no single therapy has been shown to halt the progression of this disease in all affected patients. Genetic counseling of the family members and evaluation of their blood ornithine levels which are elevated even in the presymptomatic stage when all other standard visual function tests may be normal forms an important part of management of these cases.

\section{REFERENCES:}

1. Kaiser - Kupfer MI, Caruso RC, Valle D. Gyrate atrophy of the choroid and retina. Long term reduction of ornithine slows retinal degeneration. Arch. ophthalmol. 1991: 109 (11): 1539 1548.

2. Albert Jakobiec's principles and practice of Ophthalmology $3^{\text {rd }}$ edition. Retinitis pigmentosa and allied disorder. Page no. 2239 - 2240.

3. Weleber RG, Kennaway GN, Bruist NR: Gyrate atrophy of the choroid and retina. Int. Ophthalmol 4: 23-32, 1981.

4. American Academy of Ophthalmology. The Eye M.D. Association. 2012-2013, Section-12, Chapter-11: Hereditary retinal and choroidal dystrophies. Page no. 243 - 244.

\section{AUTHORS:}

1. G. Satyavathi

2. Y. Srinivas

3. Malleswari

\section{PARTICULARS OF CONTRIBUTORS:}

1. Assistant Professor, Department of Ophthalmology, Guntur Medical College, Guntur.

2. Assistant Professor, Department of Ophthalmology, Guntur Medical College, Guntur.

3. Resident, Department of Ophthalmology, Guntur Medical College, Guntur.

\section{NAME ADDRESS EMAIL ID OF THE CORRESPONDING AUTHOR:}

Dr. G. Satyavathi, \# 12-22-17, Flat No. 6, Sri Sainadh Towers, Post Office Road, Kothapeta, Guntur-522001.

E-mail: gsatyavathi1962@yahoo.com

Date of Submission: 10/01/2015.

Date of Peer Review: 11/01/2015.

Date of Acceptance: 14/01/2015.

Date of Publishing: 19/01/2015. 